\title{
Reflection on Emergency Management in China Based on Novel Coronavirus Pneumonia Prevention and Control
}

\author{
Huan Wang* \\ College of management China West Normal University, Nan Chong 637000, Sichuan province, China. Email: \\ 850823391@qq.com
}

\begin{abstract}
In 2019, China had novel coronavirus pneumonia outbreak in Wuhan, China, which seriously threatened people's health and affected social order and economic development. The novel coronavirus epidemic has been actively dealt with by the government. However, there are still some problems, such as weak awareness of crisis, ineffective emergency response, stagnant legal construction, unsound rumors, ineffective public opinion, insufficient material support, inefficient allocation of resources, the local officials with low ability, inadequate humanistic care and incomplete rescue mechanism. By analyzing how the government deal with the novel coronavirus pneumonia crisis, we can optimize the working mechanism, improving the working methods, and improving the government's emergency management capability.
\end{abstract}

Keywords: Novel Coronavirus Pneumonia; Public Crisis; Emergency Management

\section{Introduction}

With the continuous development of globalization and human history, public crises also present a situation of high occurrence, frequent occurrence and concurrent occurrence. Countries all over the world are faced with different crisis. Governments around the world had paid more and more attention to prevent and respond to public crises effectively and improve the level of government crisis management. In December 2019, "Pneumonia of unknown cause" appeared in Wuhan, China. On January 7, 2020, "Novel coronavirus" identified by genome-wide sequencing was renamed as "COVID-19" (novel coronavirus 2019) by WHO. The outbreak of novel coronavirus in China caused the panic of hundreds of millions of people, and seriously threatening people's health and social stability. The Chinese government actively fought against the "epidemic", racing against time and the disease. This battle has given us a glimpse of "China power", but it has also taught us a lot about how governments manage crises. Although the Covid-19 crisis has not completely over, the shortcomings of the government's emergency management are quite obvious. We should seize the opportunity, sum up the experience, and improve the method and system of government crisis management.

\section{The shortcomings of government emergency management}

\subsection{Weak crisis consciousness and ineffective emergency response}

China is a vast country with close economic and cultural exchanges. Small probability events occurring at a certain time and place may also induce large-scale public crises. In recent years, China has maintained a healthy and stable development momentum. Local governments have paid more attention to economic construction than to preventing public

This is an open-access article distributed under the terms of the Creative Commons Attribution Non-Commercial License

(http://creativecommons.org/licenses/by-nc/4.0/), which permits unrestricted non-commercial use, distribution, and reproduction in any medium, provided the original work is properly cited. 
crises. At the same time, all kinds of infectious diseases such as H1N1 and H5N5 occurred in recent years are local, so that most governments tend to lower their vigilance and adopt historical inertia thinking to deal with them, thus easily missing the golden period of crisis response. At the beginning of the outbreak of the virus, some local officials concealed the truth of new virus because that they were fearing that their political performance and official status would be affected. They were consuming the trust of hundreds of millions of people.

The government of Wuhan said the pneumonia can be controlled and prevented. At the beginning, the local government did not pay attention to the unknown potential problems. They reported them according to normal procedures and waited for instructions from the superiors, which planting the hidden danger of the outbreak of the virus and missing the best opportunity for crisis management. However, at the same time, the virus has spread and a public crisis has broken out. We affirm the correctness of following procedures, but we have to question the passive attitude of local governments in the face of potential public crisis and the inadequacy of our emergency management system.

\subsection{The legal system construction is lagging behind}

When dealing with public crisis, the Chinese government attaches importance to the rule of man rather than the rule of law, and the legal construction of emergency management is lagging behind. First of all, the level of legislation is low with scattered legislation and overlapping content. Even some laws and regulations, such as the Emergency Response Law, are weak in practice. Secondly, there is a gap in the legislative content and also a lack of special legislation in relevant fields. China's emergency law attaches great importance to the handling of public crisis, ignores the prevention and the rescue and compensation of public crisis stakeholders. Many laws are very abstract, lacking supporting systems, implementation rules and measures, so that it is difficult to operate and implement in reality. The role and authority of non-governmental forces in emergency rescue has not been clearly defined in many emergency management laws, which leads to that many non-governmental forces making mistakes when they rescuing, causing the tension between the government and non-governmental organizations.

Many civil servants lack the concepts of rule of law, do not act in accordance with the law, do not actively fulfill their responsibilities, and show little respect and for life, law and human rights. For epidemic prevention, many police and community workers go on patrol with hammers. Many news videos of "hammering the mahjong table" appeared. In fact, this "way of governance" infringes on citizens' rights and interests and the spirit of the rule of law.

\subsection{Imperfect supervision of public opinion}

Due to the lack of guidance of mainstream values, the content of public opinion updates frequently and changes quickly with the emotional characteristics. Because that ordinary people are the receiver, which easily cause large-scale spread of public opinion in the society. Before the Covid-19 epidemic was officially reported, false rumors and wrong public opinion caused public panic.

There were a lot of false rumors such as smoking can protect against the virus, drinking can kill bacteria, taking antibiotics is useful for prevention, the role of "Shuang Huanglian Oral Liquid" was misread. It's difficult for citizens to distinguish news and information between true and false because of the various channels and forms. In order to increase their attention and exposure, some non-official media make use of some information they have acquired to make "first-hand real news" and influence the public mood. In order to attract attention and become famous, various we-media spread extreme and misleading information, inciting netizens with false information and foster a bad public opinion atmosphere. The current network public opinion is gradually shifting from centralization to decentralization. There is a lack of joint interaction between different information platforms, such as Douban, Zhihu, WeChat and Weibo. Even there are conflicts in information content. During the epidemic, some independent foreign forces took this opportunity to publish false statements on major information platforms, spread negative emotions, and incite and mislead the emotions of netizens.

\subsection{Insufficient material support and inefficient allocation of resources}

Scarce medical resources and a huge gap in protective clothing and masks greatly increase the risk of 
cross-infection between doctors and patients. In addition, there is an imbalance between emergency plans and resources. In the early stage of the epidemic, there was a phenomenon of "people waiting for beds" in designated hospitals. A large number of patients waiting for treatment, which result in that they delay the optimal treatment time. There is an urgent need for protective clothing and face masks. Medical workers appealed for help on the Internet, even they used file bags to making their own protective masks the families of the patients called for help on the Internet, seeking hope for their families and urging the government and hospitals to help them in time.

\subsection{Ineffective construction of the professional team}

During the epidemic, a section chief of a city disease control center left his position, took his family to Thailand to avoid the epidemic. Some officials secretly leaked information about the epidemic, causing the spreading of bad information. The leader of League of Red Cross Societies (LORCS) takes supplies of public masks to meet private needs. Wuhan Red Cross refused to accept donated materials without postage, overstocked donated materials and distributed them inefficiently and unjustly.

The professional quality of a large number of public officials in our country is cannot meet the demand of their position. China has not brought social science experts into public health emergency decision-making departments and public crisis management system. In the face of the urgent situation, medical workers gathered and went to Hubei for rescue voluntarily, which made us realize the importance of emergency rescue team. Europe and the United States both have specialized emergency management institutions. However, our emergency management system only depends on the existing administrative agency. We set up temporary emergency department to deal with public events, which is not conducive to the coordination and configuration.

\subsection{Insufficient humanistic care and incomplete rescue mechanism}

Chinese government ignores public participation and lacks the collection of public feedback. And the dialogue and communication among stakeholders are also inadequate ${ }^{[1]}$.The government provided insufficient humanistic care and psychological counseling for victims and their families. On February 9, on the way to transfer patients with severe pneumonia, community workers and government officials were not accompanied.

The work is lagging behind, disconnected and disorganized. Severe patients are emotionally unstable after a long period of waiting for treatment. A couple who went to Wuhan for treatment was stranded because of a lockdown and they even had no food to eat.

\section{Suggestions for improving the emergency management of the Chinese government}

\subsection{Set up crisis risk awareness and change the situation of responsibility seg- mentation}

In response to public health event, government departments should first establish the crisis risk consciousness, improve the ability of crisis prediction, regularly evaluate the potential risk of crisis, and constantly improve the crisis forecast and monitoring system. Establish risk communication awareness, establish long-term, stable and safe risk information exchange and communication with the public, bring training, publicity into the community, enterprise, and school to strengthen the emergency awareness of the grass-roots people. We should improve the public health system and establish a disease prevention and control system with well-established institutions and clear responsibilities from the central to local governments. We will adjust the distribution of medical institutions in urban and rural areas, and set up designated hospitals for treatment of infectious diseases in major cities. Rural health centers will be renovated, and necessary medical equipment will be purchased. Finally, the government should continue to promote the reform of administrative system, standardize emergency management process, attaches great importance to the theoretical guidance, establish emergency linkage mechanism. 


\subsection{Strengthening the legal system for emergency response}

Actively promote the legal construction of emergency response, fill the legislative gap of emergency management. Adjust inconsistencies and eliminate conflicts between different laws and regulations. We will improve the rescue and compensation system for emergencies, and formulate the Law on Disaster Relief and Compensation and the Law on Disaster Insurance. The system construction of emergency management organizations should be improved, and the responsibilities of each government department should be clarified. Affirm the dominant position of social forces in emergency rescue, bring them into the emergency management system, and clarify their response mechanism. Supporting policy documents and technical standards will be issued as a supplement to the law to make the operational steps and measures of emergency management more specific and standardized, so that every emergency management work has rules and standards to follow. In the whole process of emergency management, it is necessary to strengthen the supervision and restriction of each link, and constantly improve the efficiency of each link, so as to promote the efficient development of emergency management.

\subsection{Strengthening public opinion monitoring and control}

True and accurate information is the basis and premise of correct feedback and action. Transparency and unimpeded information are closely related to the government's emergency management. In the information society, authoritative information and efficient crisis public relations are beneficial to correctly guide the masses to overcome panic psychology.

First of all, the government should disclose information in time and make effective response with the help of media. We will strengthen the monitoring and control of public opinion, avoid the absence of information and rampant rumors, and prevent public panic and social unrest. We should increase two-way interaction with the public, accept complaints and suggestions from the masses, and conduct scientific screening and review of incidents involving public security on the Internet, and implement the handling methods of "online police + offline police". Second, a fast, timely, accurate and efficient epidemic information transmission network should be established to ensure that all infectious diseases are detected, reported, controlled and treated in time. Through the news media, the government should let the public know about the epidemic situation, master the common sense of disease prevention, understand the government's campaign plan against COVID-19 and the actual results achieved, and stabilize the social mood through accurate information. Finally, government officials should study and analyze public opinion, improve their information literacy and information control ability, and learn how to effectively communicate with the media, so as to improve the quality of government response to network public opinion.

\subsection{Improving the material support mechanism and the efficiency of resource allocation}

First of all, the government should reform the financial system, strengthen the public financial capacity of the government, set up a special fund for emergency management, to provide stable financial and material support for emergency management. Secondly, a unified material preparation and scheduling system should be established to cooperate with logistics and transportation companies to ensure the allocation of materials needed in emergency and the timely delivery of materials ${ }^{[]}$. Establish a unified resource allocation system, measure the degree of demand for emergency resources in major cities, make reasonable allocation according to regional differences, and use the network information platform for dynamic monitoring, implement dynamic management of emergency resources, and ensure the supplement and update of materials. At the same time, new media was used to build an official platform, actively listen to the voices of the people, understand the needs of the people, to meet the needs of the relief materials, and race against time to deal with the epidemic. In addition, we should make clear the key direction of resource allocation, meet the resource needs of key cities and departments, and ensure the best use of scarce resources. In the process of interaction and integration of resources, supervision should be strengthened to avoid the inflow of fake and shoddy resources in the allocation process. Administrative organs and government officials are strictly prohibited from using their power to divert emergency 
resources for other purposes. Finally, using technology and big data to improve the efficiency of allocation and utilization of resources in the period of public crisis. For example, in response to the novel coronavirus, China has saved manpower and material resources and prevented unnecessary cross-infection during the epidemic by using $5 \mathrm{G}$ medical temperature measuring, patrol robot, intelligent unmanned supermarket and etc. Finally, the government should strengthen international cooperation and actively seek support and help from international and regional organizations in terms of funds, personnel and technology.

\subsection{Strengthening education and training for public officials and building inter- connected emergency and rescue organizations}

First of all, the government should strengthen the education and practical training of public officials, strengthen the popularization of public crisis management methods and knowledge, and strive to improve the professional quality of public officials. Clarify the rights and responsibilities of each subject, build a professional and efficient emergency leading group and working group, and strengthen supervision, standardize the behavior of each subject. Using network and big data, bring experts and scholars into the network system. We will strengthen the construction of science and technology for emergency response platforms, to maximize the function of scientific research institutions, experts and scholars $^{[2]}$. To promote the diversification of participants in emergency management, integrate multiple subjects including the government, non-governmental organizations and civil society. And also actively guide multiple subjects to give play to their respective advantages and realize cooperation. At the same time, establish well-equipped, skilled and flexible medical treatment team, to cope with a variety of public health emergency management problems.

\subsection{Strengthening humanistic care and risk communication}

Strengthen humanistic care in risk communication and build mutual trust. Only by putting people's health at the center can the value of public health workers be realized to the maximum extent. Actively utilize all kinds of channels and media to collect public opinions and suggestions, improve their "public participation" ability, and enhance risk communication in public health emergency events. We should pay attention and care for the victims, their families and emergency stakeholders, and strengthen humanistic care in the process of emergency management and risk rescue ${ }^{[3]}$.

Under legal and reasonable circumstances, we should undertake the responsibility of "triple compensation": material compensation, spiritual compensation and system reform to meet the reasonable demands of relevant interest groups, win the recognition and support of the masses, and meet the reasonable demands of the masses. The government should carry out post-disaster resettlement and compensation to meet the reasonable material needs of the victims; Carry out psychological consultation and disaster relief policies and other work to meet the spiritual needs of victims; We will prevent and control at the source to reduce the risk that people will be hit by disasters again.

Under the strong leadership of the CPC Central Committee, China has fought hard to protect millions of people's lives. China has paid close attention to the implementation, assisted other countries, and demonstrated its "image as a great power" with outstanding organizational strength. "The unprecedented security measures taken by the Communist Party of China (CPC) reflect the high level of coordination among various Chinese government agencies and departments $^{[4]}$, and demonstrate the CPC's excellent governance ability," said Konurov, Central Secretary of the Communist People's Party of Kazakhstan.

Although the Chinese government's emergency management is inadequate, the author believes that a great and wise nation will surely gain experience and lessons from the disaster, and will surely reflect and make progress in the crisis. The author believes that by establishing crisis risk awareness, strengthening the construction of emergency legal system, standardizing the emergency legal system; Improving public opinion monitoring and control; Improving the material guarantee mechanism and the efficiency of resource allocation and so on, China's emergency management mechanism and public crisis management capacity will become better.

\section{References}

1. Maduka O, Maleghemi S, Komakech W, et al. Effective risk communication and contact tracing for Ebola virus 
disease prevention and control-experiences from Port Harcourt, Nigeria. Pub Health 2016; (135): 140-143.

2. Bo F, Shuang N. "Vulnerability" and "Resilience" in emergency management: From metaphor to function realization (in Chinese). Journal of Public Management 2017; (4): 129-140.

3. Ding X. Big data analysis in risk disaster crisis management and research (in Chinese). Academia Bimestrie 2018; (2): 28-35.

4. WHO. World Health Organization outbreak communication planning guide. Whqlibdoc. Who. Int. 2008; 11(3): 206-207. 